\title{
A CASA-GRANDE DOS ENGENHOS: PEDRA, TIJOLO OU PAU-A-PIQUE
}

\author{
Fernando Guerra ${ }^{i}$
}

Hilayane Barbosa Maras da Silvaii

\begin{abstract}
Resumo: A casa-grande dos engenhos, dentre as edificações tão significativas do quadrilátero açucareiro, possui arquitetura influenciada pela cultura de seus proprietários e uso do material construtivo disponível na colônia. Por meio de uma revisão da literatura e estudo iconográfico, este trabalho tem o objetivo de discutir as principais estruturas dos engenhos de açúcar e a importância do açúcar para desenvolvimento do Brasil, sendo neste momento destacado o imponente patrimônio, casa-grande, sua importância, materiais construtivos, tipologias e os recorrentes aspectos estéticos. Palavras-chave: Casa-grande; Engenhos de açúcar; Patrimônio
\end{abstract}

\begin{abstract}
The big house of the sugar mills, among the so significant buildings of the sugar quadrilateral, has architecture influenced by the culture of its owners and the use of construction material available in the colony. Through a literature review and iconographic study, this work aims to discuss the main structures of sugar mills and the importance of sugar for the development of Brazil. At this time, the imposing heritage, large house, its importance, construction materials, typologies and the recurrent aesthetic aspects are highlighted. Keywords: Big house; Sugar Mills; Patrimony
\end{abstract}

\footnotetext{
i Arquiteto e Docente do Departamento de Arqueologia UFPE.

ii Discente do Programa de PósGraduação em Arqueologia UFPE.
} 


\section{Introdução}

Os primeiros colonizadores portugueses ao chegarem ao Brasil, encontraram alguns tipos de habitações indígenas, todas bastante rudimentares e, certamente, de caráter provisório. Representavam uma manifestação cultural antes da chegada dos primeiros navegadores. Seria natural, portanto, que os portugueses reproduzissem em suas novas terras, os modelos já conhecidos de sua terra natal, adequando os edifícios ao tipo de sociedade existente, às suas necessidades, ao clima e aos materiais disponíveis a serem empregados nas novas construções.

Nos primeiros anos de colonização sobressaiu-se das demais a capitania de Pernambuco devido, sobretudo, à sua produção de açúcar. Com a ocupação holandesa e o governo do príncipe Maurício de Nassau, no século XVII, a colônia recebeu a sua primeira missão cultural, composta por inúmeros artistas como Franz Post, Peter Post, Albert Eckhout, Zacarias Wagner e tantos outros, que deixaram alguns dos mais notáveis registros pictóricos do Nordeste do Brasil, daquela época. Foram inúmeros desenhos, pinturas e documentos que retrataram as paisagens, as etnias dos habitantes da terra, a arquitetura erigida e a biodiversidade da região. Assim, conforme esses registros iconográficos, os primeiros engenhos foram movidos à água e a animais.

Naturalmente, os primeiros colonizadores, diante da imensidão de terras disponíveis, puderam escolher àquelas que melhor se adaptassem para a implantação dos seus engenhos e, certamente, teriam optado pelos engenhos movidos à água, porque além de fornecer a energia, os rios serviam de meios de transporte do açúcar produzido até os portos de onde seria exportado à Europa. Além dos rios, os primeiros engenhos deveriam ser implantados na proximidade de onde seria extraída a madeira para alimentar as fornalhas.

Dentre as edificações tão significativas do quadrilátero açucareiro, a casa-grande, não tão mais significativa quanto às outras, possuía arquitetura influenciada pela cultura de seus proprietários.

A partir do final do século XVIII, o Nordeste recebe um modelo de casa-grande que apresenta em seu programa capelas conjugadas, modelo este mais comum no norte de Portugal. Um detalhe a ser observado nessas edificações é o acesso exclusivo dos membros da família do senhor de engenho ao espaço religioso. 
Muitas dessas capelas foram erigidas no mesmo plano das casas, formando um conjunto de uma leitura contínua e harmoniosa, como no engenho Poço Comprido, em Vicência-PE. Todavia, em sua grande maioria, as capelas encontram-se isoladas das casas, em local de destaque no terreno.

As técnicas construtivas empregadas foram generalizadas para essas edificações, ou seja, paredes em alvenaria de pedras ou tijolos cerâmicos maciços; cobertas com estrutura de madeira com telhas cerâmicas e pisos em pedra ou lajotas de barro. Tais técnicas dependiam, certamente, da disponibilidade do material encontrado na região.

Na primeira metade do século XIX, com a presença da Corte portuguesa na cidade do Rio de Janeiro e a Abertura dos Portos as nações amigas, a colônia passaria por profundas mudanças em seus aspectos sociais, políticos e econômicos. Com a chegada de novos contingentes populacionais, novos hábitos e diferentes linguagens e, sobretudo, novos estilos, a arquitetura ganha caracteres europeus e a novidade, então, espalha-se por todas as regiões do novo império.

Em decorrência de tais acontecimentos, uma outra casa-grande surge, agora, com uma traça europeia que seria o bangalô, o sobrado neoclássico e o chalé, utilizando-se em suas construções os novos materiais surgidos a partir da Revolução Industrial. Muitas dessas notáveis edificações já foram destruídas ou se encontram em estado de ruínas, demolidas pela ignorância e pelo descaso dos homens por desconhecerem o seu valor como um patrimônio cultural do País.

\section{A casa-grande dos engenhos: pedra, tijolo ou pau-a-pique.}

Em Pernambuco, o termo casa-grande, de origem incerta, possui um dos primeiros registros no Inventário de Armas e Apetrechos Bélicos que os holandeses deixaram em Pernambuco e dos prédios edificados ou reparados até 1654, publicado em 1940, conforme revela Geraldo Gomes (1998):

\footnotetext{
Nesse documento, onde só existem referências a edifícios urbanos, encontram-se, frequentemente, expressões como casas-grandes de sobrado, casas-grandes de dois sobrados e, no mesmo documento, surgem também casas de sobrado e, casas pequenas de sobrado, o que indica que grandes eram as casas, quer fossem térreas ou com sobrados. No mesmo documento, há um único registro de uma grande casa, que é, com certeza e
} 
devido à sua descrição, o Palácio da Boa Vista construído por Maurício de Nassau, no Recife. (Gomes, 1998:84).

No século XIX, o inglês Henry Koster, em seu trabalho "Viagens ao Nordeste do Brasil" (1942), usa largamente o termo "Casa-Grande" em referência à residência do Senhor de engenho. Vauthier (1975), no mesmo século, faz referências em relação à casa-grande, como a residência do Senhor de engenho.

Louis-Léger Vauthier fez inúmeros relatos em relação às técnicas construtivas das casasgrandes dos engenhos, observando que embora o tijolo tenha sempre preferência, muitas vezes encontram-se paredes de pedra argamassadas com barro, até a altura do primeiro andar e, frequentemente, paredes de pau-a-pique, o que demonstra o uso, em muitas casas, de argamassa mista nas edificações.

Como exemplo de uso de mais de um sistema construtivo com mais de uma técnica, poder-seia citar o Engenho Poço Comprido (século XVIII), em cujo andar térreo é utilizado nos pilares tijolos, enquanto no superior utilizou-se a taipa de pau-a-pique (Vauthier, 1975:87).

Já o termo "casa de vivenda", foi utilizado pelo Imperador D. Pedro II, em 1859, quando da sua viagem ao norte do Brasil, para designar a casa-grande dos Senhores de engenho daquela parte do país.

A taipa foi uma técnica construtiva das mais usadas na época da colonização brasileira. Tem sua origem em tempos remotos no Oriente, sendo levada pelos árabes à Península Ibérica quando da sua ocupação, após derrotarem os visigodos, em 711.

A taipa de mão, também chamada de pau-a-pique, taipa de sopapo ou taipa de sebe, é uma técnica em que as paredes são armadas com madeira diversas ou bambu e preenchidas com barro e fibra vegetal.

Na taipa de pilão há a compressão da terra em formas de madeira como uma grande caixa, na qual o barro é vertido e socado em camadas de até $20 \mathrm{~cm}$, aproximadamente. Em seguida, aplicam-se pequenas madeiras roliças envolvidas em folhas (geralmente de bananeiras), produzindo orifícios cilíndricos para a confecção de novas paredes. Por ser um sistema construtivo mais rápido e diante da grande disponibilidade de madeiras existente, a taipa de pau-a-pique foi o sistema construtivo mais usado em todo o período colonial brasileiro. 
De uma maneira geral, os sistemas construtivos trazidos pelos portugueses para a colônia podem ser "classificados" de duas maneiras: um mais apurado, mais requintado, diga-se, erudito e outro popular. O erudito estava representado, em grande parte, pelos Engenheiros Militares que, através do conhecimento dos tratados renascentistas, edificaram as inúmeras fortalezas localizadas ao longo da costa para a defesa da colônia, bem como os edifícios religiosos erigidos, mostravam essa erudição na arquitetura da colônia.

O sistema popular estava representado pelos Mestres de Ofício, homens experientes em obras na Metrópole, que transmitiam aos seus aprendizes as técnicas de construção com os materiais disponíveis. Assim, as casas-grandes, as capelas, as moitas e as senzalas, e mais alguns outros exemplares, constituíram o repertório edificante dos mestres. Poderiam, então, utilizar a pedra ou o tijolo, nos seus sistemas construtivos.

No século XVI, em Pernambuco, era comum o uso de tijolos maciços em algumas construções de senhores mais abastados, confeccionados em inúmeras olarias. Em Olinda, por exemplo, existia uma olaria no Convento de São Francisco, com tijolos de dimensões consideráveis.

Evaldo Cabral de Mello revela que:

A arquitetura civil, urbana como rural, também foi, como demonstrou Robert C. Smith, a mera transplantação da portuguesa. Os engenhos levantados a partir do surto açucareiro iniciado na década de setenta (séc. XVII) já não exibiam aquelas casas-fortes que a Coroa mandara edificar para que recolhesse a população em caso de ataques da indiada. As casasgrandes que pintará Frans Post já eram... uma transcrição quase literal do tipo mais comum das casas rurais da mãe pátria,... marcado... desde o Minho e Trás-os-Montes e por toda a Beira Alta e a Beira Baixa... pelas mesmas características: os mesmos esteios no andar térreo usado para depósito, as varandas abertas e as escadas externas, quer no centro, quer num dos ângulos da fachada, e os mesmos telhados de quatro águas e cumeeira do Pernambuco do século XVII. Tipo de habitação que persistiu já entrado o século XIX, embora passasse a ser construído com material nobre e se acomodasse melhor às exigências de conforto doméstico de um grupo social que entrementes se ruralizara. Quando isto acontecer, virão também se impor outros estilos de construção reinol, como os solares, que persistiram até o século XIX, antes da adesão à moda dos bangalôs e chalés, trazida pelos ingleses para suas residências de arrabalde. (Mello, 2002:8485).

Portanto, a arquitetura civil de Portugal, tanto urbana como rural, legou ao Brasil, certamente, as casas de engenho com alpendres ou varandas erigidas pelos construtores e mestres-deobras, nas áreas ribeirinhas, nas várzeas e na área rural, onde os espaços de circulação (as varandas e os alpendres) poderiam, também, ser utilizados como espaços de contemplação da 
paisagem no entorno da edificação: Solar da Quinta do Sabadão - Ponte de Lima, Portugal; Solar de São Paulo de Figueiredo - Guimarães, Portugal, mas foi através da iconografia holandesa retratando os engenhos de açúcar de Pernambuco, com os pintores da comitiva do Conde Nassau, que os holandeses conseguiram deixar uma farta e rica documentação possibilitando, assim, a identificação de inúmeros tipos e composições arquitetônicas erigidas em Pernambuco, a partir do século XVI.

No Brasil, só há registros consistentes de casas rurais térreas, com varandas em três lados, a partir do século XIX, no qual alguns pintores da Missão Francesa conseguiram retratar inúmeros exemplares de casas avarandadas nos arredores do Rio de Janeiro, como Debret, Taunay, entre outros. Essas casas avarandadas, de maneira mais irrestrita, foram alvo de comentários de viajantes estrangeiros, como Mawe (1944), mineralogista inglês, que visitou o Brasil entre os anos de 1809 e 1810, revelava:

As ruas eram, em princípio, atravancadas por balcões de grade de aparência muito pesada, impedindo a circulação do ar, mas foram retiradas por ordem do governo. Em consequência de sua situação baixa, de imundície das ruas o Rio de Janeiro não podia ser considerável saudável. (Mawe, 1944:106).

Muitas dessas casas com varandas, conforme depoimento de inúmeros viajantes que estiveram no Brasil no século XIX foram construídas nos arredores das cidades portuárias como o Recife, Salvador e Rio de Janeiro, seguindo, certamente, gostos e estilos europeus e, em sua maioria, lusitanos. Indubitavelmente, a presença de estrangeiros no Brasil, sobretudo os ingleses no século XIX, contribuiu largamente para a mudança de antigos hábitos, gostos e costumes arraigados aos brasileiros, proporcionando-Ihes um novo modo de vida, do ponto de vista social e cultural.

As casas-grandes, na verdade, àquelas dos antigos engenhos de Pernambuco, do período colonial brasileiro, edificadas nos séculos XVI e XVII, que chegaram até aos dias atuais, são consideradas muito raras. Conhece-se, em sua grande maioria, como já referenciado, através das pinturas dos artistas holandeses trazidos na comitiva do Conde Nassau, por ocasião da presença holandesa em Pernambuco, no século XVII.

As inúmeras casas que se encontram ainda em uso, salvo se existir algum exemplar mais antigo, objeto de estudo mais recentes remontam ao século XIX. Assim, surgiram tipos/exemplares que foram classificados morfologicamente. Os tipos, as características 
morfológicas e os programas das casas foram decorrentes das necessidades funcionais de cada família naquela época.

Um dos tipos de casas mais antigos, conforme Geraldo Gomes (1998) é:

O de casas nortenhas, devido à sua semelhança com as casas rurais do norte de Portugal. $O$ edifício parece provisório, e pode tê-lo sido, considerando-se as circunstâncias do seu surgimento... Os primeiros engenhos, na várzea do Capibaribe, próxima ao Recife, não precisavam possuir casas sólidas nem grandes, pois os seus proprietários residiam na cidade. Daí as observações dos holandeses sobre o pouco caso que os portugueses faziam de suas vivendas, privilegiando as fábricas. (Gomes, 1998: 85-49).

O programa básico dessas casas era composto de: no térreo - as paredes laterais subiam até o andar superior e, no centro, elementos de suporte, pilares de madeira ou de alvenaria de tijolos e uma escada interna; no andar superior - surge uma varanda de sacada no centro da fachada ou em uma das extremidades, geralmente voltada para a moita e demais aberturas, portas e janelas. Tais casas desapareceram ao longo dos anos e a sua existência é conhecida apenas através de gravuras holandesas do século XVII.

Outro tipo citado pelo arquiteto Geraldo Gomes (1998) conduz a dois notáveis exemplares: a casa-grande do engenho Passassunga, no município de Bom Jardim (agreste pernambucano), e a do engenho Poço Comprido, no município de Vicência. Tais exemplares possuem um programa semelhante com uma escada externa que se eleva a uma varanda no centro da fachada superior e demais aberturas - portas e janelas - aparecem ao lado e por traz dela a varanda. No térreo, os espaços são mais fechados - as paredes se elevam até o andar superior e possui alguns vãos abertos, portas e janelas, compõem as fachadas. Na casa do engenho Poço Comprido, surgem, no térreo, alguns arcos em uma composição central, além de ter, em anexo, uma capela em estilo Rococó, com cimalha ondulada e frontão escalonado, dedicada no princípio a Santana e atualmente a São João Batista.

Ainda surgiram, no período do Brasil Colônia, as casas de Torres, que apresentavam em sua planta-baixa duas torres nas extremidades do corpo central. Com dois pavimentos, podiam ser construídas em alvenaria de tijolos ou em pedra com telhados - telhas de barro cozido distribuídos em seus volumes mais altos - os das torres - em quatro águas. No século XVII, as raríssimas que existiram em Pernambuco foram retratadas por Franz Post, a exemplo da casagrande do engenho Megaípe (uma edificação ainda do final do século XVI). 
No início do século XX, a casa-grande do engenho Megaípe de Baixo foi retratada pelo pintor pernambucano expressionista Mário Nunes, cujo quadro se encontra no Palácio do Campo das Princesas, do Governo do Estado de Pernambuco. Em 1928 ela foi demolida pelo usineiro João Lopes Siqueira Santos, conforme relato do genealogista, historiador e membro do Instituto Arqueológico Histórico Geográfico Pernambucano - IAHGP, Reinaldo Carneiro Leão (2019, entrevista), carecendo de um trabalho arqueológico para aflorar os seus alicerces e deixá-los à mostra para visitação pública.

\section{Os Solares}

São edificações de dois andares construídas no Brasil, entre os séculos XVII e XIX, com ampla similitude com as casas urbanas e rurais portuguesas. Apresentam em sua composição arquitetônica dois pavimentos, suportes (pilares) em alvenaria de tijolos ou de pedra, planta com traça retangular, coberta em quatro águas com beirais com estrutura em madeira, cobertura em telhas tipo canal e com pisos: no térreo, geralmente utilizavam tijoleiras e no andar superior, estrado de madeira.

A casa solar de Santa Maria e Solar dos Arcos em Bragança, Portugal; e a Casa-Grande do Engenho Morenos, em Pernambuco são exemplos dignos de nota. Em muitos casos, no pavimento térreo, era comum surgirem algumas seteiras - aberturas estreitas na parede para dar passagem à luz. Esse espaço térreo, contudo, era considerado como a área social da casa, local onde se reuniam os familiares. Na parte posterior da casa localizava-se a cozinha e demais dependências de serviço.

Algumas construções apresentavam uma série de arcadas em seu pavimento térreo e, portanto, poderiam ser denominadas de sobrados sobre arcadas. Compunham-se de dois pavimentos erguidos em alvenaria de tijolos ou pedra, bem como em alvenaria mista, telhado em quatro águas e pisos; no térreo tijoleiras e no pavimento superior estrado de madeira. Uma das edificações mais notáveis entre os solares é a casa-grande do engenho Madalena, no Recife - PE. (Figura 1) Esse imóvel, em sua traça original do século XVIII, como relato do Dr. Ayrton Carvalho:

Apresentava as suas paredes externas e internas do pavimento térreo, todas erigidas e apoiadas em arcos plenos de alvenaria de tijolos. Sofrendo uma intervenção de reforma no século $X X$, os seus arcos foram todos emparedados e as paredes receberam revestimento em azulejos. Na década 
de 60 (século XX), o edifício foi restaurado para receber o Instituto do Patrimônio Histórico e Artístico Nacional (IPHAN), momento em que foram retirados os rebocos que cobriam os arcos, deixando-os, em sua grande maioria, aparentes (Carvalho, 1962: entrevista).

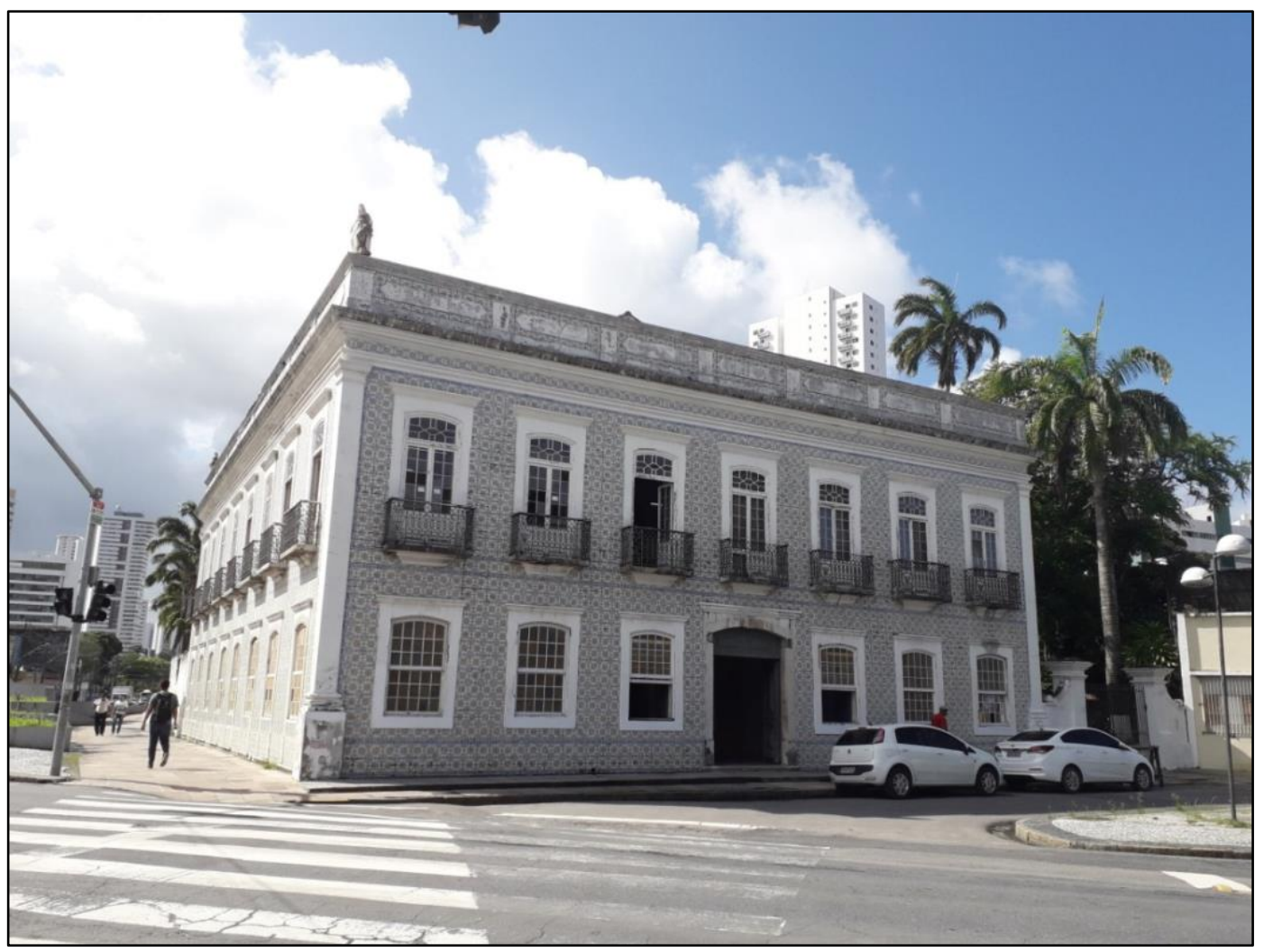

Figura 1: Casa-grande do engenho da Madalena. Foto: Hilayane Maras, 2019.

Um exemplar dos mais significativos trazendo arcadas no pavimento térreo é a casa-grande do engenho Monjope, situada no município de Igarassu, Pernambuco. (Figura 2) Uma arquitetura similar - arcadas na fachada frontal - era encontrada na casa-grande do engenho Camaragibe, hoje inteiramente modificada em seu aspecto original, sendo alvo de um projeto para ser implantado um Centro Cultural, de autoria do arquiteto José Luiz Mota Menezes.

Um tipo muito comum de casa-grande com planta retangular e alpendre em seu entorno é encontrado em inúmeros municípios do interior do Estado. Construídas no século XIX, apresentam um pavimento térreo com coberta em estrutura de madeira em quatro águas e cobertura em telha de barro. Alguns exemplares trazem um porão, que elevam o piso em estrado do pavimento térreo, sendo utilizado como depósito. Os alpendres no entorno da edificação apresentam em grande parte, colunas bem trabalhadas erguidas em tijolos com fustes cilíndricos e capitéis com equino e ábaco, que suportam o frechal contínuo. Alguns ainda são guarnecidos por uma balaustrada criando, assim, agradáveis locais de convivência. 
Alguns municípios como Cabo de Santo Agostinho, Vicência, Aliança, Buenos Aires e Água Preta, guardam ainda exemplares desse tipo de edificação.

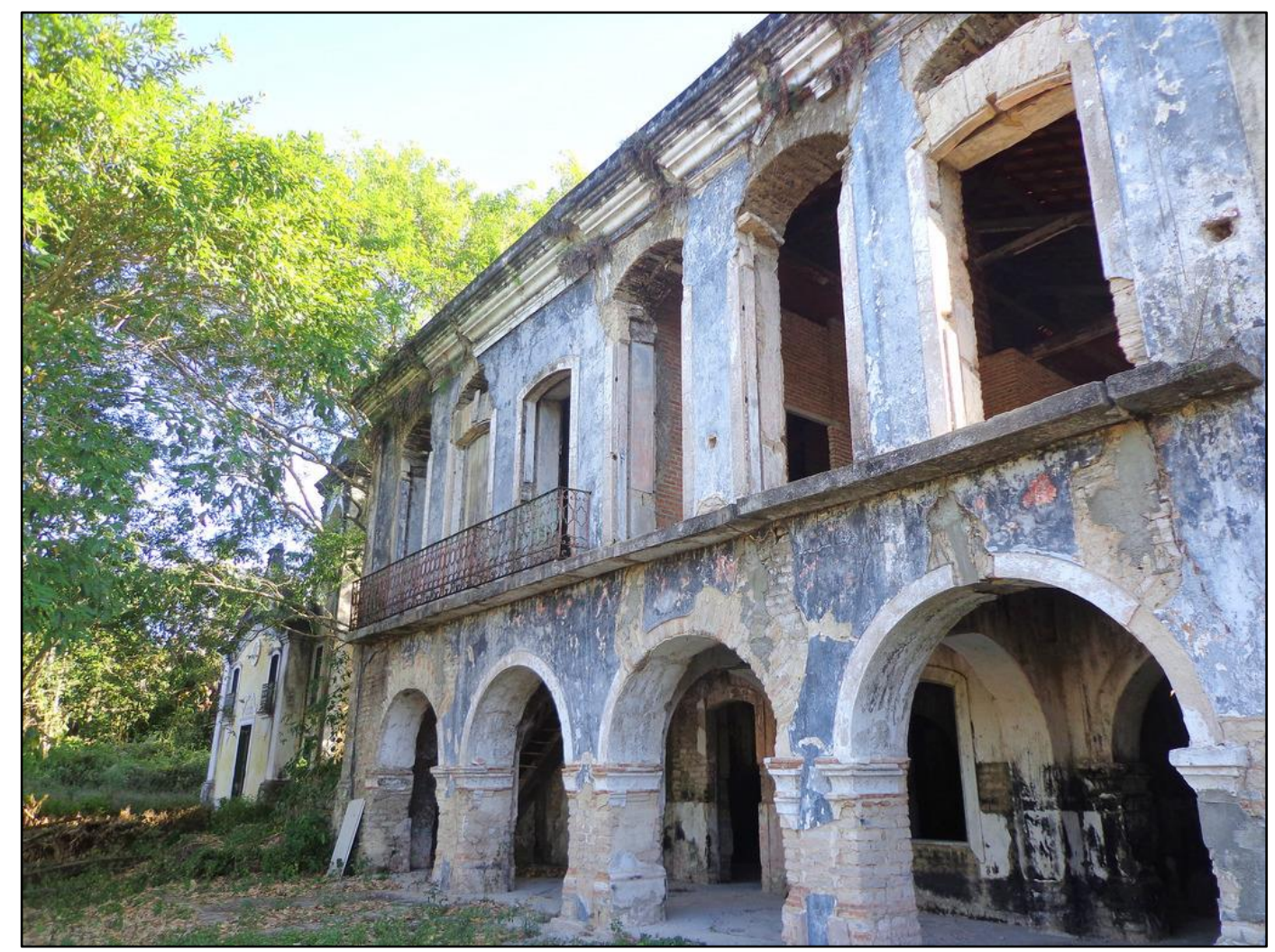

Figura 2: Casa-grande do engenho Monjope. Foto: Fernando Guerra, 2019.

No município de Escada - Mata Norte do Estado - encontram-se uma das mais notáveis construções do século XIX, entre os engenhos pernambucanos: a casa-grande do engenho Sapucaji. Construída dois pavimentos e porões no térreo - servindo de depósitos - tem uma imensa varanda apoiada por colunas de ferro e gradil de proteção, com uma elegante escada de acesso. Em sua fachada frontal, ao nível da varanda, além da porta central, existem doze janelões, seis de cada lado, em extraordinário equilíbrio e harmonia de composição. Outro exemplar que merece destaque entre as casas de engenho, é a casa-grande do engenho São José, no município de Sirinhaém, no litoral Sul de Estado. Em dois pavimentos, apresenta o térreo um pouco mais recuado do alinhamento das arcadas de tijolos que suportam o andar superior da varanda, cuja coberta em quatro águas é apoiada por colunas de alvenaria de tijolos distribuídas elegantemente ao longo de toda a varanda.

Um grupo de casas-grandes construídas no século $X X$ foi erguido em alguns municípios de Pernambuco, apresentando uma traça com plantas retangulares, único pavimento, cobertura 
com estrutura em madeira e recobrimento com telhas de barro, telhado em quatro águas e paredes com alvenaria de tijolos dobradas e alpendres. Estes alpendres no entorno da edificação, têm seus telhados mais baixos do que aqueles do corpo central. Como exemplo tem-se a casa-grande de engenho Novo da Conceição, no município de Moreno, Pernambuco.

No final do século XIX e início do século XX, surgiram os tipos chamados de chalés. Apresentam um único pavimento - podendo ter um pequeno porão utilizado para depósito - paredes em alvenaria de tijolos e estrutura de coberta em madeira. A cobertura em duas águas, com telhas de barro tipo canal, expõe uma extensa cumeeira perpendicular à fachada frontal da casa. Um detalhe peculiar nessas casas é o desenho dos alpendres, com telhados mais longos e independentes, cobrindo as varandas que envolvem o corpo da casa, constituindo com estas varandas agradáveis espaços de convivência. Um belo exemplar é a casa-grande chalé do engenho Gravatá, no município de Água Preta, na Mata Sul de Estado. Muitas delas podem apresentar nas fachadas alguns adornos em massa e lambrequins nas extremidades do telhado.

Alguns exemplares raríssimos na arquitetura de Pernambuco foram erigidos com um pátio interno, um agradável espaço de ventilação, a exemplo da casa-grande do engenho Bastiões, em Ribeirão, município da Mata Sul do Estado.

Em Portugal encontram-se inúmeras casas do século XVI ao XVIII com as capelas anexas. Em Viana do Castelo, por exemplo, a Casa Malheiro Reimão ou Casa da Capela das Malheiras, também conhecida como a Casa da Praça é um belo exemplar da arquitetura barroca da cidade, com o brasão da família na fachada e capela anexa.

A capela ligada à casa por um dos lados, apresenta uma fachada com frontão com volutas e coroamento entalhado em pedra na base do cruzeiro, ornada por coruchéus bulbosos em sua extremidade e guarnecida por cunhais com capitéis. O portal com ombreiras e coroamento decorados é encimado por uma grande janela vertical, emoldurada com cercaduras com entalhes concheados, conferindo-Ihe um conjunto belo e harmonioso.

Outro exemplo admirável é a casa da Família Vasconcelos, em Torre de Moncorvo, no Distrito de Bragança, com a Capela de Nossa Senhora dos Prazeres anexa. A elegante capela mostra uma fachada com portal emoldurado por pilares com caneluras e capitéis jônicos, com verga horizontal decorada com baixos relevos em ponta de diamantes, com datação de 1714, 
encimada por um frontão triangular interrompido com inscrições das armas da família. Acima do imóvel, ergue-se uma sineira tipo espadana.

Outras localidades em Portugal encerram alguns exemplares como: Braga (Freguesia de São João do Souto) com a Casa dos Coimbras e Capela de Nossa Senhora da Conceição ou Capela dos Coimbras; Olivença/Olivenza com a Casa do Castelo e Capela de Santa Maria do Castelo; Vila Real com a Capela de Santa Ana que está anexada ao edifício da Santa Casa da Misericórdia e a Casa do Despacho (século XVI) com a Capela da Misericórdia anexa; Galveias com a Capela da Misericórdia e o Infantário Dona Anita e tantas outras.

No Brasil, a presença da capela anexa à casa, certamente sofreu influência por meio dos exemplares portugueses, chegando na colônia por volta do século XVI. Naquele século, um dos cinco primeiros engenhos de Pernambuco, o Jaguaribe foi construído nas terras das Sesmarias Jaguaribe, pelo português Vasco Fernandes de Lucena. No interior da casa-grande, em ruínas, ainda se pode ver a primeira capela anexa à sala com a invocação de Nossa Senhora de Guadalupe.

Mais tarde, possivelmente no século XVIII, ergue-se uma segunda capela em local próximo à casa das Sesmarias Jaguaribe, encontrada por meio de escavações arqueológicas realizadas no terreno que, segundo Henry Koster (1942), tinha a devoção dedicada a Santo Antônio. Constata-se, pois, que as consideráveis distâncias entre as casas rurais e as urbanas foram as causas das construções das capelas nas residências rurais, por devoção e para uso da família e demais integrantes da casa.

Por muitos anos, assim, a capela esteve no interior da habitação integrando-se à intimidade familiar. A partir do século XVIII as capelas deixam o interior da casa e vem localizar-se ao lado da residência, compondo ainda uma fachada contínua. Além de Minas Gerais (nas cidades históricas), Pernambuco guarda inúmeros exemplos - a setecentista casa-grande do engenho Poço Comprido com a capela anexa, bem como no engenho Monjope, dentre tantos outros engenhos no Estado.

No século XIX, criam-se os oratórios em um espaço no interior da habitação, local onde se reunia a família e convidados para as orações diárias. Algumas casas em Igarassu, Olinda e no Recife, ainda podem ser encontrados essas obras de arte. No espaço urbano de Olinda, em seu sítio histórico, o elemento sagrado ainda é amplamente representado, através da simbologia 
das "capelas dos passos da paixão", lembrando os passos na Via Sacra, espalhadas entre as suas ruas e ladeiras.

\section{Considerações Finais}

A casa-grande dos engenhos de açúcar, imponente patrimônio nacional, sempre despertou certo fascínio como um exemplar de arquitetura desde a sua construção, por ser a morada do senhor de engenho, espaço arquitetural e casa de vivenda onde abrigava e reunia a família mais importante do local. Por meio dos quadros pintados pelos artistas da comitiva de Nassau no século XVII, se conhecem inúmeros exemplares, constituindo-se, portanto no maior registro iconográfico dessas habitações no Nordeste. Vale ressaltar que os tipos retratados já deveriam existir desde os primeiros anos de colonização, trazidos pelos portugueses como exemplares de sua terra natal. Eram erigidas, geralmente, em dois pavimentos, com telhados em quatro águas e varanda no meio da fachada, no pavimento superior. No térreo estava o depósito e eram construídas em pedra, tijolos ou taipa de pau-a-pique. Alguns raríssimos exemplares poderiam apresentar uma torre, uma espécie de casa fortificada de origem na Europa Medieval.

Ao longo dos anos, muitas dessas casas de vivenda desapareceram no Nordeste, sobretudo àquelas do século XVIII, as quais traziam em sua traça a capela conjugada ao interior da habitação, podendo ainda ser encontrada no interior de São Paulo e na região de Minas Gerais.

A partir do século XIX, o Brasil sofreu profundas modificações sociais e econômicas, sobretudo com a chegada da Corte portuguesa a cidade do Rio de Janeiro e a Abertura dos Portos as nações amigas, em 1808, com a chegada do Rei D. João V e de sua comitiva de 15.000 pessoas.

No burgo colonial, viviam em torno de 50.000 pessoas, o que revelou, na época, o grande burburinho com a presença de tantos lusitanos para serem acomodados. Mas, no clima de festa de acolhimento, a Colônia começou a ganhar vida nova. Portanto, dentre as primeiras novidades tem início a introdução nos engenhos de máquinas a vapor para a moagem da cana, e também as máquinas que seriam usadas nos vagões pelas ferrovias, conduzindo o açúcar produzido nos engenhos aos portos de embarque. Definitivamente, a Colônia se afastaria do isolamento. 


\section{Referências}

CARVALHO, A. 1962 .Ayrton Carvalho: depoimento. Entrevista cedida a SOUZA, F. G. Nov. de 1962.

GOMES, G. 1998. Engenho e arquitetura. Recife: Massangana.

KOSTER, H. 1942. Viagens ao nordeste do Brasil. São Paulo: Ed. Nacional, 1942.

LEÃO, R. C. 2019. Reinaldo Carneiro Leão: depoimento. Entrevista cedida a SOUZA, F. G. Jan de 2019.

MAWE, J. 1944. Viagens ao Interior do Brasil: Principalmente aos Distritos do Ouro e dos Diamantes. Tradução de Solena Benevides Viana; Introdução e Notas de Clado Ribeiro de Lessa. Rio de Janeiro: Zélio Valverde.

MELLO, E. C. 2002. Um Imenso Portugal: História e Historiográfica São Paulo: Editora 34.

VAUTHIER, L.L. 1975. Casas de residência no Brasil. In: Arquitetura Civil I (Textos escolhidos da Revista do Instituto do Patrimônio Histórico e Artístico Nacional). São Paulo: Universidade de São Paulo. 